\title{
Mediastinitis, pseudo-aneurysm formation, aortic bleed, and death from endoscopic botulinum toxin injection
}

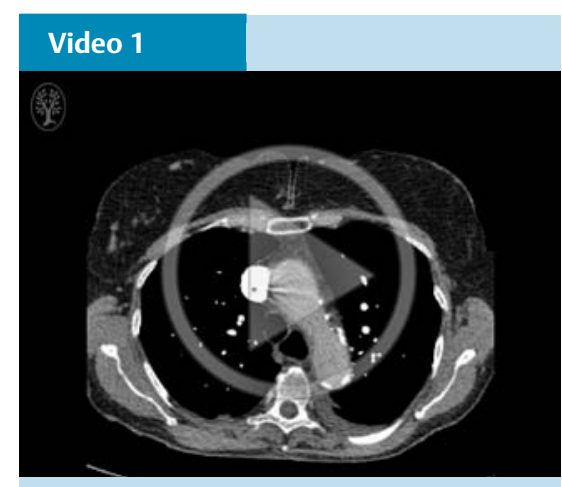

Initial computed tomography pulmonary angiogram showed no obvious pulmonary emboli. There were inflammatory changes around the esophagus suggesting mediastinitis, but no obvious source of bleeding. In retrospect, a small 7-mm thoracic aorta pseudo-aneurysm was seen at the level of the left atrium $(0: 36 \mathrm{~s})$.

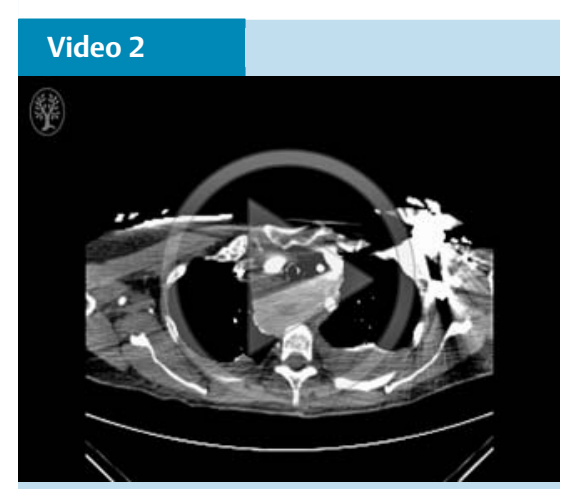

Computed tomography aortic angiogram showed a large 22-mm aortic pseudo-aneurysm at the same level as the previous $7-\mathrm{mm}$ pseudo-aneurysm $(0: 26 \mathrm{~s})$. This had increased in size and ruptured, resulting in the hematoma and inflammatory mass around the entire length of the esophagus. The left atrium was compressed by this mass, which contributed to cardiac arrest.

Endoscopic botulinum toxin injection is considered a safe and viable option for the management of achalasia [1,2]. Although esophageal perforation and mediastinitis are well-documented complications of this treatment, pseudo-aneurysm formation of the thoracic aorta following intersphincteric injection is exceedingly rare [3]. We report the first published fatality from a thoracic aorta pseudo-aneurysm bleed following inter-sphincteric botulinum toxin injection. Endoscopists should

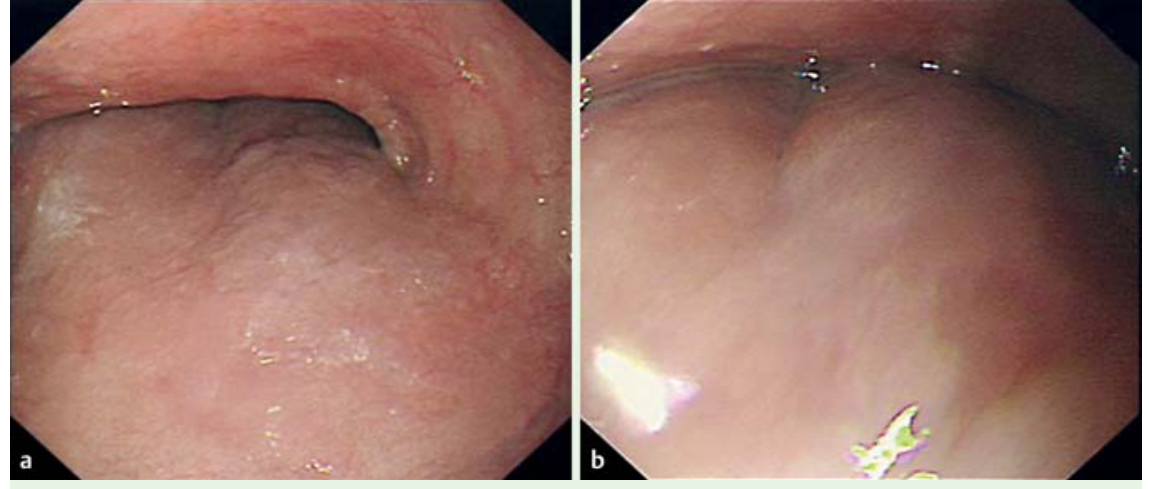

Fig. 1 Esophagogastroduodenoscopy images taken near the level of the gastroesophageal junction. a Narrowing of the lumen with the corresponding external compression from the hematoma. $\mathbf{b}$ Further extrinsic obstruction of the esophagus.

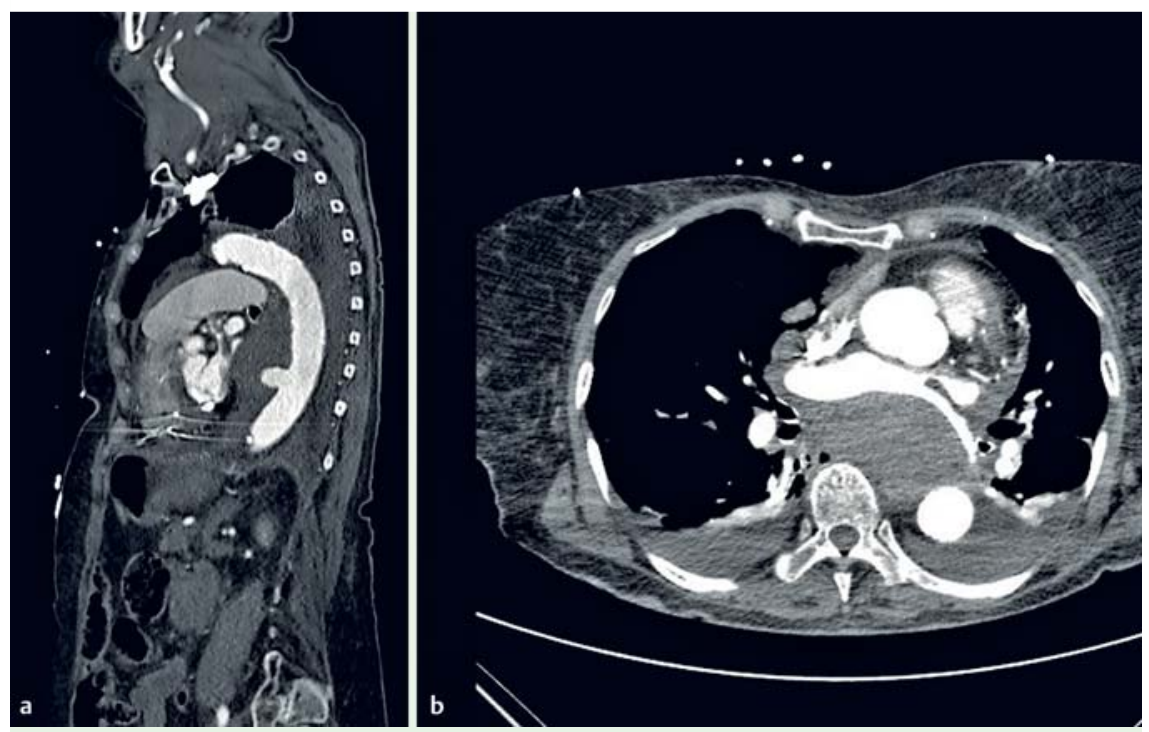

Fig. 2 Computed tomography (CT) images. a A sagittal slice from the $\mathrm{CT}$ angiogram further demonstrated the 22 -mm pseudo-aneurysm and inflammatory mass. $\mathbf{b}$ A transverse slice from the $\mathrm{CT}$ angiogram at the level of the left atrium showed extrinsic compression.

be vigilant of this potentially fatal complication.

An 89-year-old woman with a background of previous myocardial infarction and a permanent pacemaker for complete heart block complained of severe left scapular pain and pleuritic right chest pain 8 days after an endoscopic botulinum toxin injection. The toxin had been injected into the four quadrants of the lower esophageal sphincter using a $5 \mathrm{~mm}$ needle (25 units into each quadrant). She had undergone 3-monthly endoscopic botulinum toxin injections for the previous 8 years.
A chest radiograph showed no acute abnormalities. A computed tomography (CT) pulmonary angiogram revealed inflammatory changes around the esophagus suggesting mediastinitis without gas bubbles to prove perforation. There was also a small 7-mm aortic pseudo-aneurysm (found only in retrospect) ( Video 1 ). She was started on intravenous meropenem. Discussions with a cardiothoracic tertiary center confirmed the decision of conservative management and agreed with the choice of antibiotic. 
The patient then underwent esophagogastroduodenoscopy, which showed an extraluminal swelling that was probably a hematoma ( $\mathbf{F i g .} \mathbf{1})$. She rapidly deteriorated and suffered a pulseless electrical activity cardiac arrest. After return of spontaneous circulation, a contrast CT aortic angiogram revealed a $22-\mathrm{mm}$ pseudo-aneurysm of the descending aorta at the level of the left atrium, with extensive hematoma along the entire length of the esophagus and compression of the left atrium causing inflow obstruction to the heart ( $\bullet$ Fig. 2, $\bullet$ Video 2 ). The patient was unsuitable for surgical intervention. After discussion with the family, the decision was made to provide palliative treatment, and the patient died soon after.

Endoscopy_UCTN_Code_CPL_1AH_2AJ

Competing interests: None
Mark Z. Y. Tan' ${ }^{1}$, Jennifer Whitgift' ${ }^{2}$, Hugh Warren ${ }^{2}$

${ }^{1}$ Critical Care Unit, Central Manchester University Hospitals NHS Foundation Trust, Manchester, United Kingdom

${ }^{2}$ General Surgery Department, Queen Elizabeth Hospital King's Lynn, King's Lynn, United Kingdom

\section{References}

1 Pehlivanov N, Pasricha PJ. Achalasia: botox, dilatation or laparoscopic surgery in 2006. Neurogastroenterol Motil 2006; 18: 799 804

2 Vaezi MF, Pandolfino JE, Vela MF. ACG clinical guideline: diagnosis and management of achalasia. Am J Gastroenterol 2013; 108: $1238-1249$

3 Chao CY, Raj A, Saad N et al. Esophageal perforation, inflammatory mediastinitis and pseudoaneurysm of the thoracic aorta as potential complications of botulinum toxin injection for achalasia. Dig Endosc 2015; 27: $618-621$
Bibliography

Dol http://dx.doi.org/ 10.1055/s-0042-107074

Endoscopy 2016; 48: E186-E187

(c) Georg Thieme Verlag KG

Stuttgart · New York

ISSN 0013-726X

Corresponding author Mark Z. Y. Tan, MBBS, BSC, MRCS Critical Care Unit Central Manchester Universities NHS Foundation Trust Oxford Road Manchester M13 9WL United Kingdom Fax: +44-161-1234578 mark.tan@cmft.nhs.uk 